\title{
Administration of systemic steroids during hospitalization does not improve the clinical outcome in patients with Covid-19
}

\author{
Ranjit BANWAIT 1,2 (D), Sad ALQUADAN 1,2 (D), Sarah WILSON 3 (D), Dhaval UPADHYAY 1,2 (D), \\ Devina SINGH 1, 2 (D), Rima PATEL 2 (D), Christopher BRAY 1, 2 (D), Hale Z. TOKLU 1, 2 * \\ 1 Department of Graduate Medical Education, College of Medicine, University of Central Florida, Orlando, USA. \\ 2 North Florida Regional Medical Center, Gainesville, USA. \\ 3 Department of Graduate Medical Education, HCA Healthcare, Nashville, USA. \\ * Corresponding Author. E-mail: hale.toklu@ucf.edu (H.Z.T.); Tel. +1-352-333 4825. \\ ** Ranjit Banwait and Sad Alquadan have shared co-first authorship.
}

Received: 19 December 2020 / Revised: 04 May 2021/ Accepted: 08 May 2021

\begin{abstract}
The systemic steroids are recommended for cases with refractory septic shock or severe acute respiratory distress syndrome. Although systemic glucocorticoids help to resolve inflammation and treat cytokine storm, the time course for steroid use and which patients benefit from using systemic corticosteroids is unclear. In this study, we aimed to evaluate the therapeutic effect of corticosteroids in COVID-19 patients. Electronic medical records of hospitalized patients $(n=7,980)$ from 178 hospitals across United States for confirmed COVID-19 between January 1st 2020 and May 8th 2020 were reviewed. Of the 7,980 patients, 3,951 (49.5\%) were female and 4,029 (50.5\%) were male. The mean age was $57.4 \pm 19$ years. Fifteen percent $(n=1,219)$ died in hospital or were discharged to hospice care. Seventy-two percent $(n=5,774)$ required non-ICU level of care, while $28 \%(n=2,206)$ of patients required ICU, and of those $1,157(14.5 \%)$ needed ventilator support. The mean length of stay in the hospital was 6 days (range $0-84$ days). Fourteen percent $(n=1111)$ of patients received at least one dose of systemic steroids during hospitalization. Sixty precent of those had ICU level of care with 435 (39\%) requiring ventilator support. Overall, the use of corticosteroids was associated with increased mortality $(\mathrm{OR}=1.273 ; \mathrm{p}=0.0160)$ and 3.53 days longer hospital stay $(\mathrm{p}<0.0001)$. The corticosteroid exposed group was also noted to progress to a higher level of care and have longer time on a ventilator when compared with the patients who did not receive steroids. The length of hospital stay and mortality was higher especially in severe/critical patients. Based on these results, we recommend cautious use of corticosteroids in COVID-19. The etiology behind this association is still unclear and presents an area for future research.
\end{abstract}

KEYWORDS: Steroids; COVID-19; SARS-CoV-2; ventilation; hospital stay; mortality; coronavirus.

\section{INTRODUCTION}

The coronaviruses are RNA viruses that are responsible for zoonotic infections. The strains associated with severe respiratory symptoms and recent outbreaks include severe acute respiratory syndrome coronavirus (SARS-CoV) in China in 2002-2003 and Middle East Respiratory Syndrome coronavirus (MERS$\mathrm{CoV}$ ) in Saudi Arabia in 2012 [1]. Most recently, a novel severe acute respiratory syndrome coronavirus 2 (SARS-CoV-2) causing coronavirus disease 2019 (COVID-19) emerged as an outbreak in late 2019 in Wuhan, China.[1] It quickly evolved into a pandemic spreading rapidly worldwide [1-3]. As of May 4th, 2021, a total number of 32,228,003 cases of COVID-19 have been reported in the United States of America including 574,220 deaths [4].

Patients with COVID-19 exhibit symptoms varying from mild upper respiratory symptoms to severe illness requiring mechanical ventilation [5, 6]. Severe cases of COVID-19 typically involve acute pneumonic processes with extensive radiological opacity (ground-glass opacity) and, on autopsy, diffuse alveolar damage, inflammatory infiltrates, and microvascular thrombosis.

Despite a concerted effort from the international medical community, a consensus on a standard treatment regimen for COVID-19 has yet to be agreed upon. Several agents including RNA polymerase inhibitors (remdesevir, favipiravir, ribavirin), protease inhibitors (lopinavir/ritonavir), antimalarial drugs

How to cite this article: Banwait R, Alquadan S, Wilson S, Upadhyay D, Singh D, Patel R, Bray C, Toklu HZ. Administration of systemic steroids during hospitalization does not improve the clinical outcome in patients with Covid-19. J Res Pharm. 2021; 25(6): 841-851. 
(chloroquine, hydroxychloroquine), antibacterials (azithromycin, teicoplanin), interferons, plasmapheresis, and steroids are under investigation [7-12]. However, their efficacy is disputable.

As with other viral infections, cytokine release and activation of innate immune response play important roles in the prognosis of COVID-19. Huang et al, reported the cytokine storm in critically ill COVID19 patients [13]. Thus, it was postulated that immunomodulatory therapy, including corticosteroids, may be helpful to down-regulate the pathological release of the cytokines due to their anti-inflammatory effects [14]. Thus, corticosteroids are typically used to treat severe acute respiratory infections of viral etiology [15-17]. On the other hand, they can also delay viral clearance, because of their immunosuppressant effects. They can increase the risk of secondary infections, and inversely affect the length of hospital stay and the survival [1617].

Understanding the use of corticosteroids in patients with COVID-19 is of the utmost importance. In this study, we investigated the efficacy of steroid use and timing of the treatment.

\section{RESULTS}

In the present study, 7,980 confirmed COVID-19 positive patients were stratified by disease severity and use of corticosteroids, (see cohort diagram in Figure 1). The general characteristics of the patients are summarized in Table 1.

Table 1. Demographical information on study population. The percentage was calculated based on the known data per strata.

\begin{tabular}{|c|c|c|c|c|}
\hline & & All Patients & Corticosteroids & No Corticosteroids \\
\hline COVID-19 positive $(n, \%)$ & & $7980(100)$ & $1111(13.9)$ & $6869(86.1)$ \\
\hline Age (mean $\pm S D)$, range & years & $57.43 \pm 19.2[0-90]$ & $63.87 \pm 16.1[18-90]$ & $56.40 \pm 19.5[0-90]$ \\
\hline \multirow{2}{*}{$\operatorname{Sex}(n, \%)$} & Female & $3951(49.5)$ & $531(47.8)$ & $3420(49.8)$ \\
\hline & Male & $4029(50.5)$ & $580(52.2)$ & $3449(50.2)$ \\
\hline \multirow{4}{*}{ Race/Ethnicity (n, \%) } & Caucasian & $2796(35.0)$ & $404(36.4)$ & 2392(34.8) \\
\hline & African American & $2063(25.9)$ & $277(24.9)$ & $1786(26.0)$ \\
\hline & Hispanic & $2175(27.3)$ & $316(28.4)$ & $1859(27.1)$ \\
\hline & Others & 946 (11.9) & $114(10.3)$ & $832(12.1)$ \\
\hline \multirow{4}{*}{ Smoking status (n, \%) } & Never smoker & $4904(61.5)$ & $610(54.9)$ & $4299(62.6)$ \\
\hline & Former smoker & $1202(15.0)$ & $248(22.3)$ & $954(13.9)$ \\
\hline & Current smoker & $525(6.6)$ & $75(6.8)$ & $450(6.6)$ \\
\hline & Unknown & $1344(16.9)$ & $178(16.0)$ & $1166(17.0)$ \\
\hline $\begin{array}{l}\text { Total number of } \\
\text { comorbidities (mean) }\end{array}$ & & 1.76 & 2.66 & 1.62 \\
\hline \multirow{3}{*}{$\begin{array}{l}\text { COVID-19 disease severity } \\
(\mathrm{n}, \%)\end{array}$} & Mild/Moderate & $5774(71.6)$ & $440(39.6)$ & $5334(77.6)$ \\
\hline & Severe & 1012 (12.7) & $222(19.9)$ & $790(11.5)$ \\
\hline & Critical & $1194(15.0)$ & $449(40.4)$ & $745(10.8)$ \\
\hline ICU level of care (n, \%) & & $2206(27.6)$ & $671(60.4)$ & $1535(22.3)$ \\
\hline Vasopressor support (n, \%) & & $37(0.5)$ & $14(1.3)$ & $23(0.3)$ \\
\hline $\begin{array}{l}\text { Mechanical Ventilator use } \\
(n, \%)\end{array}$ & & $1157(14.5)$ & $435(39.1)$ & 722 (10.5) \\
\hline Time on Mechanical & $<24$ hours & $129(11.1)$ & $29(6.6)$ & $100(13.9)$ \\
\hline Ventilator (n, \%) & $24-96$ hours & $265(22.9)$ & $94(21.6)$ & $171(23.7)$ \\
\hline & $>96$ hours & $763(65.9)$ & $312(71.7)$ & $451(62.5)$ \\
\hline $\begin{array}{l}\text { Total length of hospital } \\
\text { stays (mean } \pm S D \text { ), range }\end{array}$ & days & $6.01 \pm 7.32[0-84]$ & $12.24 \pm 8.9[0-57]$ & $5.00 \pm 6.5[0-84]$ \\
\hline Died or Hospice care $(n, \%)$ & & $1219(15.3)$ & $352(31.7)$ & $867(12.6)$ \\
\hline
\end{tabular}

\subsection{COVID-19 disease severity}

Of the 7,980 patients, 5,774 (72\%) had mild/moderate symptoms, 1,012 (13\%) had severe symptoms, and 1,194 (15\%) were critical. The variables that were found to have an association with increase in disease severity included age, male sex, number of comorbidities, and corticosteroid use during hospitalization (Table 2). Patients on corticosteroids during their hospitalization were 0.233 times less likely to remain at a lower disease severity ( $95 \%$ CI $0.205-0.265$; p value $<0.0001$ ) than those not receiving steroids. In other words, patients not receiving corticosteroids were 4.3 times more likely not to progress to higher level of care, including ICU and in some cases ventilator/vasopressor support, when compared to patients receiving corticosteroids (95\% CI $3.775-4.889$; p value $<0.0001)$. 


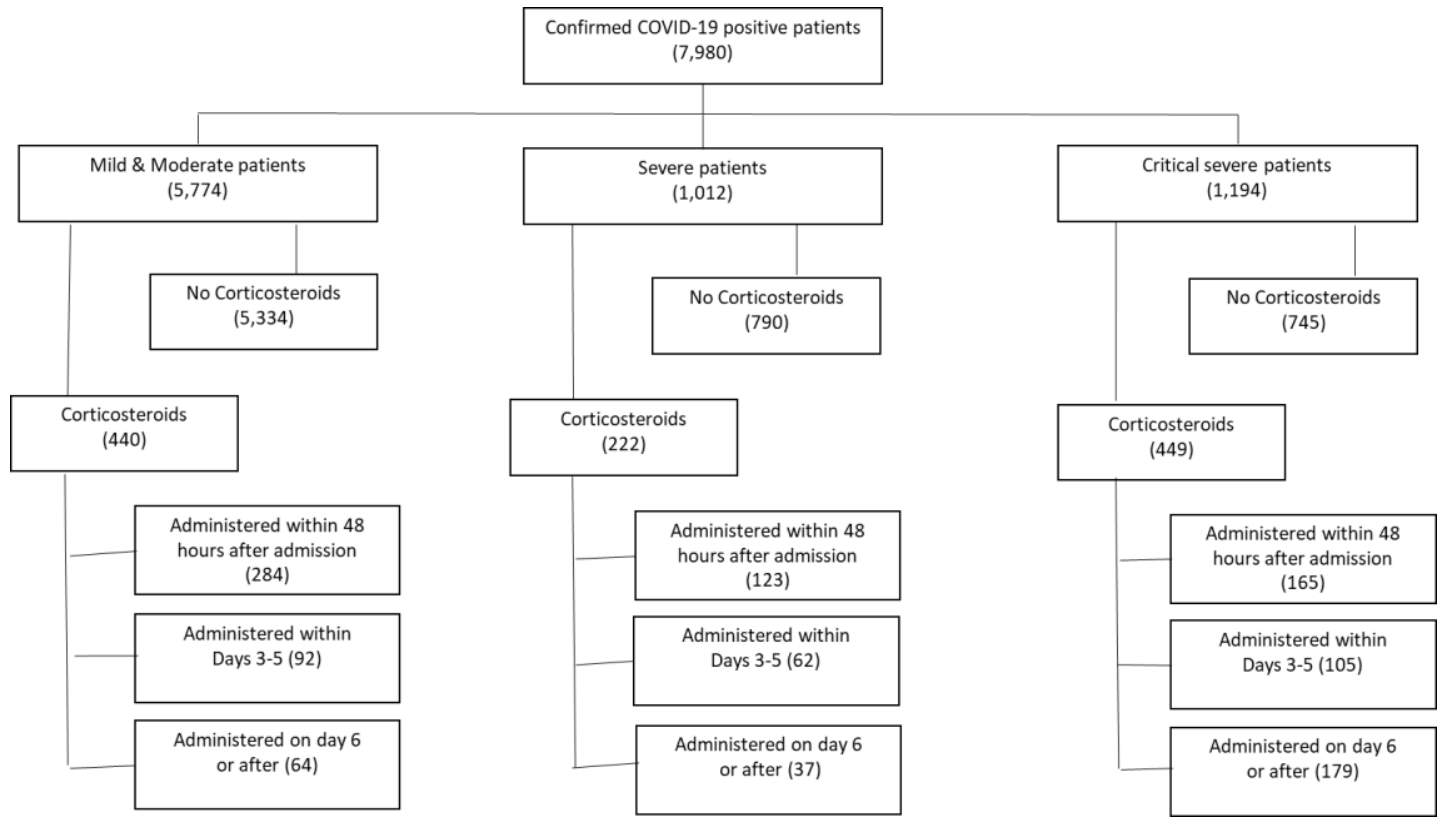

Figure 1. Flow diagram of study population extracted from the medical records in $\mathbf{1 7 8}$ hospitals across USA. The number of patients in each group are given in parenthesis. Disease severity: Mild/moderate: Highest level of care being emergency department or medical floor; Severe: The highest level of care being intensive care unit (ICU); Critical: The highest level of care being ICU and requiring mechanical ventilation and/or vasopressor support.

When a subgroup analysis was performed with 1,111 patients who received corticosteroid therapy, patients receiving their first dose of corticosteroids within the first 48 hours of admission were 3.8 times more likely to have a lower disease severity when compared to patients receiving corticosteroids on day 6 or after (95\% CI 2.864 - 5.101; p value <0.0001) (Table 2).

\subsection{Time on ventilator}

Of the 1,157 patients who needed ventilator support, 129 (11\%) required it for $<24$ hours, $265(23 \%)$ required it for 24-96 hours, and $763(66 \%)$ required it for $>96$ hours (Table 1). Variables that were found to have an association with increased time on a ventilator included increasing age, being an 'ever smoker', and corticosteroid use during hospitalization (Table 2). Overall, when compared to the patients not receiving corticosteroids, patients on corticosteroids were 0.64 times less likely to have a decreased time on a ventilator ( $95 \%$ CI $0.493-0.827$; p value $=0.0007)$. In other words, patients not receiving corticosteroid were 1.6 times more likely to have decreased time on ventilator when compared to those given steroids (95\% CI 1.209 - 2.027; $\mathrm{p}$ value $<0.0007$ ) (Table 2).

In a subgroup analysis of ventilated patients with severe/critical disease and receiving corticosteroids within 48 hours of admission, there was no significant difference in time spent on the mechanical ventilator (OR 0.882; 95\% CI 0.623 - 1.250; $\mathrm{p}=0.4812$ ) (Table 3).

\subsection{Length of hospital stay}

The mean length of stay in the hospital was approximately 6 days for the whole study population (Table 1). There was an association found between increase length of hospital stay and age, male sex, number of comorbidities, disease severity and corticosteroid use during hospitalization (Table 2). Patients on corticosteroids exhibited a length of stay in the hospital 3.53 days longer than those not receiving steroids $(p$ value $<0.0001$ ) (Table 2 ).

When considering timing of initiation of corticosteroids, patients that received their first dose of corticosteroids within the first 48 hours were found to have a total length of stay 7.14 days less than patients that received their first dose of corticosteroids on day 6 or after ( $p$ value $<0.0001$ ). Similarly, patients that received their first dose of corticosteroids on days $2-5$ were found to have a total length of stay 5.07 days less than patients that received their first dose of corticosteroids on day 6 or after ( $p$ value $<0.0001$ ) (Table 3 ). 


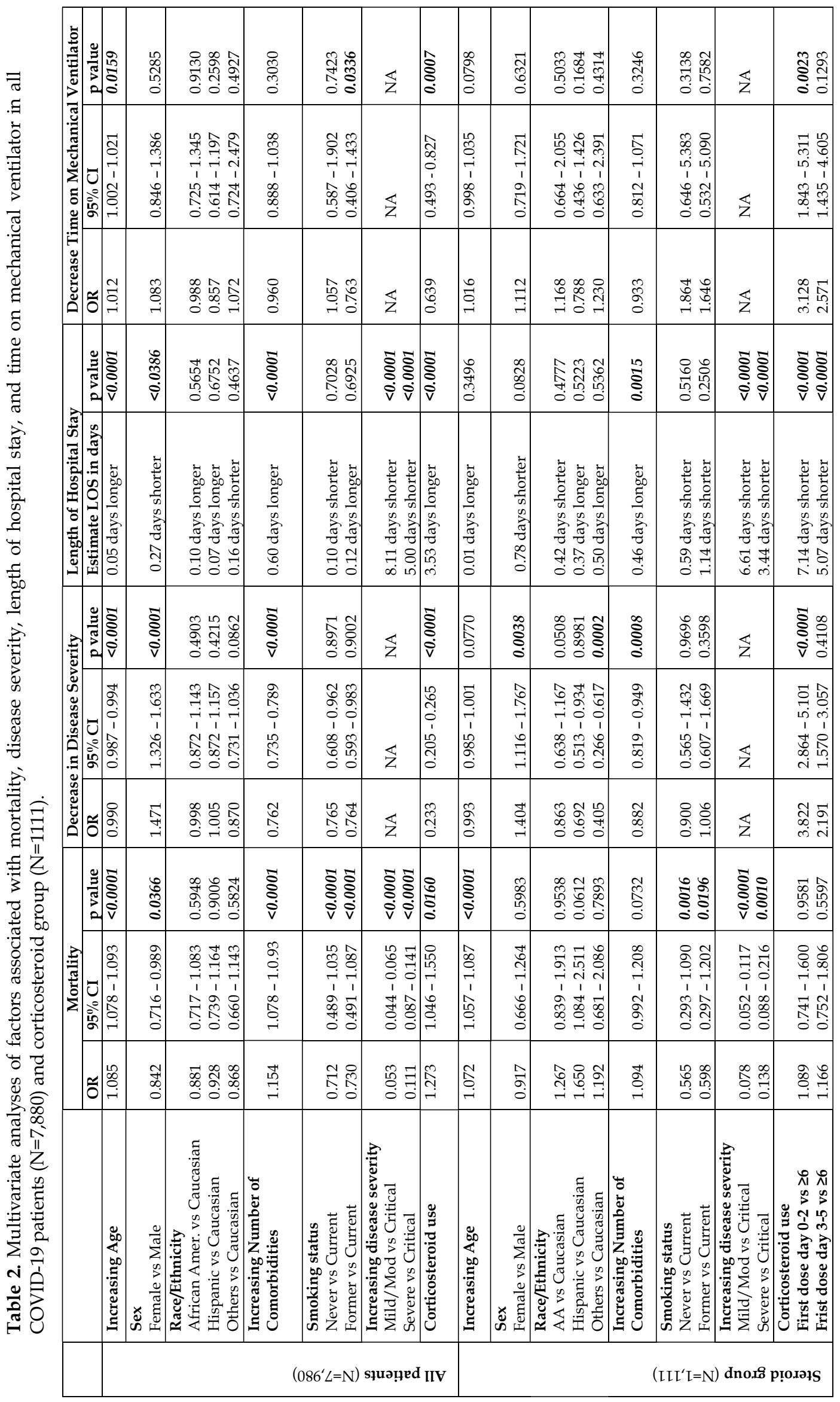


Table 3. Association between corticosteroid treatment within the first 0-2 days of admission and time on mechanical ventilator in patients with Severe to Critical COVID-19 disease severity.

\begin{tabular}{lcccc}
\hline $\begin{array}{l}\text { Disease } \\
\text { Severity }\end{array}$ & $\begin{array}{l}\text { Corticosteroid } \\
\text { Exposure }\end{array}$ & $\begin{array}{l}\text { Mechanical Ventilator } \\
\text { use }(\mathbf{N}=845)\end{array}$ & OR (95\% CI) & p value \\
\hline & Yes $(\mathrm{N}=338)$ & $<24$ hours $(\mathrm{N}=14)$ & & \\
& $24-96$ hours $(\mathrm{N}=48)$ & & \\
Severe/Critical & & $>96$ hours $(\mathrm{N}=112)$ & $0.882(0.623-1.250)$ & 0.4812 \\
$(\mathrm{~N}=1873)$ & & $<24$ hours $(\mathrm{N}=87)$ & & \\
& No $(\mathrm{N}=1535)$ & $24-96$ hours $(\mathrm{N}=160)$ & & \\
& & $>96$ hours $(\mathrm{N}=424)$ & & \\
\hline
\end{tabular}

In a subgroup analysis, patients with mild/moderate disease and receiving corticosteroids within the first 48 hours had a hospital length of stay 1.8 days longer than the non-steroid group ( $\mathrm{p}$ value $<0.0001)($ Table 4). Similarly, patients with severe/critical disease and receiving corticosteroids within the first 48 hours had a hospital length of stay 1.9 days longer than the non-steroid group ( $p$ value <0.0001) (Table 4).

Table 4. Association between corticosteroid treatment within the first 0-2 days of admission and length of hospital stay of patients with Mild to Moderate vs Severe to Critical COVID-19 disease severity.

\begin{tabular}{|c|c|c|c|c|c|}
\hline $\begin{array}{l}\text { Disease } \\
\text { Severity }\end{array}$ & $\begin{array}{l}\text { Corticosteroid } \\
\text { Exposure }\end{array}$ & $\begin{array}{c}\text { Mean length of } \\
\text { hospital stay }\end{array}$ & $\begin{array}{l}\text { Estimate length of } \\
\text { hospital stay }\end{array}$ & $\begin{array}{l}\text { R-square } \\
\text { value }\end{array}$ & p value \\
\hline $\begin{array}{l}\text { Mild/Moderate } \\
\quad(\mathrm{N}=5659)\end{array}$ & $\begin{array}{l}\text { Yes }(\mathrm{N}=325) \\
\text { No }(\mathrm{N}=5334)\end{array}$ & 3.71 days & $\begin{array}{l}1.76 \text { days longer LOS in } \\
\text { corticosteroid group }\end{array}$ & 0.1787 & $<0.0001$ \\
\hline $\begin{array}{l}\text { Severe/Critical } \\
\quad(\mathrm{N}=1873)\end{array}$ & $\begin{array}{l}\text { Yes }(\mathrm{N}=338) \\
\text { No }(\mathrm{N}=1535)\end{array}$ & 10.47 days & $\begin{array}{l}1.86 \text { days longer LOS in } \\
\text { corticosteroid group }\end{array}$ & 0.0384 & $<0.0001$ \\
\hline
\end{tabular}

\subsection{Mortality}

Overall mortality was $15 \%(n=1,219)$. The increase in mortality was associated with age, male sex, number of comorbidities, smoking status, COVID-19 disease severity, and corticosteroid use during hospitalization (Table 2). Patients given corticosteroids were 1.3 times more likely to die when compared to patients not given corticosteroids when controlled for other variables (95\% CI 1.046 - 1.550; $\mathrm{p}$ value $=0.0160$ ).

When looking at timing of initiation of corticosteroids, there was no statistical significance between the groups who received corticosteroids within the first 48 hours ( $p$ value $=0.9581$ ) or within days $2-5$ ( $p$ value $=0.5597$ ) compared to patients receiving corticosteroids on day 6 or after (Table 2 ).

In a subgroup analysis of patients with mild/moderate disease (non-ICU) and receiving corticosteroids within the first 48 hours, there was no association between corticosteroid use and mortality $(p$ value $=0.5220)$ (Table 5). However, patients with severe/critical disease (ICU setting) and receiving corticosteroids within the first 48 hours, were 1.433 times more likely to die than those without corticosteroids (95\% CI 1.090 - 1.883 ; $\mathrm{p}$ value $=0.0099)($ Table 5$)$.

Table 5. Association between corticosteroid treatment within the first 0-2 days of admission and mortality in patients with Mild to Moderate vs Severe to Critical COVID-19 disease severity.

\begin{tabular}{|c|c|c|c|c|c|}
\hline $\begin{array}{l}\text { Disease } \\
\text { Severity }\end{array}$ & $\begin{array}{l}\text { Corticosteroid } \\
\text { Exposure }\end{array}$ & $\begin{array}{l}\text { Survivors } \\
(\mathrm{N}=5294)\end{array}$ & $\begin{array}{l}\text { Non-survivors } \\
(\mathrm{N}=365)\end{array}$ & OR $(95 \% \mathrm{CI})$ & $p$ value \\
\hline \multirow{2}{*}{$\begin{array}{l}\text { Mild/Moderate } \\
(\mathrm{N}=5659)\end{array}$} & Yes $(\mathrm{N}=325)$ & 292 & 33 & \multirow{2}{*}{$1.156(0.741-1.804)$} & \multirow[t]{2}{*}{0.5220} \\
\hline & No $(\mathrm{N}=5334)$ & 5002 & 332 & & \\
\hline \multirow{2}{*}{$\begin{array}{l}\text { Severe/Critical } \\
(\mathrm{N}=1873)\end{array}$} & Yes $(\mathrm{N}=338)$ & 188 & 150 & \multirow{2}{*}{$\begin{array}{l}1.433(1.090-1.833) \\
\text { increase in mortality in } \\
\text { corticosteroid group }\end{array}$} & \multirow[t]{2}{*}{0.0099} \\
\hline & No $(N=1535)$ & 1000 & 535 & & \\
\hline
\end{tabular}

\section{DISCUSSION}

To our knowledge, this study presents the largest number of COVID-19 positive patients in the USA on corticosteroid therapy. Previously, corticosteroid therapy has been shown to reduce mortality in adults with severe community-acquired pneumonia.[16] However, the evidence for its utility in influenza and other viral pneumonia, specifically SARS and MERS, is insufficient $[17,18]$. The variability of the innate response between individuals and/or variability in the response to different pathogens may be the reason for controversial findings. 
The use of steroids is considered a double-edged sword; and caution should be exercised until further evidence specific to COVID-19 patients emerges [19, 20]. Currently, the World Health Organization (WHO) suggests avoiding routine use of corticosteroids, but does recommend its use in cases with refractory septic shock or severe acute respiratory distress syndrome (ARDS) [21]. Hence, during the current COVID-19 pandemic, many therapeutic protocols in the setting of ICUs and Infectious Disease Departments include the use of systemic corticosteroids for the treatment of moderate to severe respiratory insufficiency, as indicated in ARDS [22].

One of the earliest pieces of evidence on the use of corticosteroids in coronavirus, came from the SARS epidemic in China in 2002-2003. The study of 401 patients with SARS-CoV infections showed the efficacy of glucocorticoids in only severe cases. Even though no benefit was seen on the overall mortality rate and hospital length of stay, the subgroup analysis of 152 critical cases demonstrated decreased mortality and hospital length of stay after adjustment for possible confounders [23].

Hopeful of similar beneficial outcomes with the use of corticosteroid in previous coronavirus pandemics, studies are just starting to come out regarding the use of corticosteroids in COVID-19 from China [24-29], Greece [14], Spain [30], the UK [31], and the USA [32, 33]. These studies have provided some early data on the use of corticosteroids; however, the results have been controversial. Limitations include relatively small patient populations and a multitude of different types of corticosteroids used via different routes and at different dosages and frequencies. Along with these factors, the timing of the initiation of corticosteroids from admission and corticosteroid usage in patients with different disease severity has also been widely varied. Prospective studies are still lacking to support any claim of benefits or risks involved in use of corticosteroids in COVID-19.

The first of the six studies from China came from Wuhan Union Hospital.[24] This study found that early administration of methylprednisolone $(1-2 \mathrm{mg} / \mathrm{kg} / \mathrm{d}$ for $5-7$ days) improved the clinical outcome in patients with COVID-19 [24]. The results included rapid return of normal body temperature and improvement in peripheral capillary oxygen saturation. Chest CT scans showed improved absorption focus. The second study from China by Zha et al involved 31 patients, 11 of whom were given $40 \mathrm{mg}$ of methylprednisolone once or twice per day within 24 hours of admission for a median of 5 days [25]. The study concluded that corticosteroid treatment did not influence virus clearance time, duration of symptoms, or hospital length of stay in patients with mild COVID-19. Of note, this study only included patients with mild COVID-19 disease severity and had a younger patient population (median age, 39 years). Additionally, $73 \%$ of the corticosteroid group also received moxifloxacin. The third study included 25 COVID-19 patients receiving oral or IV methylprednisolone for a median duration of 7 days. There was no statistically significant difference found in viral clearance between patients receiving corticosteroids and the control group [26]. However, another group from Shanghai found that 5 patients treated with prednisolone or dexamethasone had delayed clearance of viral RNA in their stools compared to that in oropharyngeal swabs [27]. Wu et al conducted a retrospective cohort study of 201 patients with COVID-19. This study found that treatment with methylprednisolone $(\mathrm{n}=62)$ decreased the risk of death among patients with ARDS. Nevertheless, the study is limited by small sample size and lacks the specific dose, duration, and route of methylprednisolone [28]. Despite these early studies claiming some beneficial effects of corticosteroid use in COVID-19 patients, the study by Liu et al was unable to prove any radiological improvement in the lung images of the 40 patients receiving IV methylprednisolone (30-80 mg/kg/day) [29].

Based on the data derived from the above studies, the National Health Commission of China formulated the Diagnosis and Treatment Protocol for Novel Coronavirus Pneumonia (Trial Version 7). Cautious use of corticosteroids are recommended for only critically ill patients (e.g., those with progressive deterioration of oxygenation indicators). Specific recommendations include use of low-to-moderate doses (no more than 1-2 $\mathrm{mg} / \mathrm{kg} /$ day methylprednisolone or equivalent) and for a short duration (3-5 days) [34].

Similar to the experience in China, several studies are starting to come out of Europe. In a series of 6 cases from Greece, patients who received IV methylprednisolone (125 mg/day for 3-5 days) exhibited better clinical outcomes. The authors concluded that the result was due to the reversal of the cytokine storm. However, 5 of these patients also received azithromycin [14]. A single center retrospective study from Spain included 396 COVID-19 patients who were treated with corticosteroids and had significantly lower in-hospital mortality than controls (13.9\% versus $23.9 \%$ ). There was no significant difference between initial regimens of $1 \mathrm{mg} / \mathrm{kg}$ /day of methylprednisolone or equivalent and glucocorticoid pulses [35]. In late June 2020, a preliminary report was published from a randomized, controlled but open-label trial conducted in the United Kingdom called the Randomized Evaluation of COVID-19 Therapy (RECOVERY). To date, this has been the 
largest study on the topic. Patient population included 2,104 patients randomly allocated to receive $6 \mathrm{mg}$ of dexamethasone once daily for up to ten days and a comparative control group of 4,321 patients receiving usual care. Preliminary data from the trial suggested that dexamethasone reduced 28-day mortality rates among patients receiving invasive mechanical ventilation or oxygen at randomization, but not among those not requiring respiratory support [31].

The first study from the USA evaluated short-term dexamethasone use in 21 patients in a hospital in Rhode Island. Selected patients with hypoxic respiratory failure were administered dexamethasone $(4 \mathrm{mg}$, three times a day for 2 days) and showed improved outcomes [32]. The second study included 213 patients with 132 receiving corticosteroids in the early phase. Moderate and severe-critically ill patients received hydroxychloroquine and IV methylprednisolone $(0.5-1 \mathrm{mg} / \mathrm{kg} /$ day) in 2 divided doses for 3 to 7 days. They found significant reduction in the median hospital length of stay with the early corticosteroid treatment [33].

Our study is the most recent from the USA and has the largest population of COVID-19 patients $(n=7,980)$. Contrary to the recent beneficial effects claimed in the studies summarized above, we observed worse outcomes with the usage of corticosteroid therapy in patients diagnosed with COVID-19.

In our study population of 7,980 confirmed COVID-19 patients, 1,111 (14\%) patients received at least one dose of corticosteroid during their hospitalization. The timing of the initiation of corticosteroid therapy, progression of disease severity, use of mechanical ventilator, time on ventilator, length of hospital stay, and mortality were studied. Results from our study indicated that patients who received corticosteroid therapy during their hospitalization were more likely to progress to higher level of disease severity, which includes ICU level of care and mechanical ventilator/vasopressor support. Use of corticosteroid therapy was also linked to increase in time on ventilator, 3.5 days longer hospital stay, and 1.3 times increase in mortality.

Based on the initial findings, we conducted a subgroup analysis looking at the timing of initiation of corticosteroids to see if there is a window of opportunity where use of corticosteroid may be beneficial. We divided our patient population into those receiving corticosteroids within 48 hours, between days 3-5, and on day 6 or after admission. Compared to the patient population receiving corticosteroids 6 days or more from admission, patients receiving corticosteroids within 48 hours of admission did markedly better in terms of being less likely to progress to higher levels of disease severity, which included ICU level of care and mechanical ventilator/vasopressor support. They were also likely to have less time on a ventilator and a shorter stay in the hospital. In the group of patients receiving corticosteroids on days 3-5, statistical significance was found only in a shorter length of hospital stay when compared to patients receiving corticosteroids on day 6 and after. Of note, there was no statistical significance in mortality for patients receiving corticosteroids within 48 hours or on day 3-5 when compared to patients receiving steroids on day 6 or after. Our analysis pointed out the fact that although the use of corticosteroids in general was associated with worse outcomes (first analysis), patients receiving corticosteroids on day 6 and after did far worse compared to patients who received corticosteroids early in admission. We further investigated the administration of corticosteroids in the first 48 hours of admission to patients receiving no corticosteroids by level of COVID-19 disease severity. Of the 5,659 patients that were considered mild to moderate (non-ICU) COVID-19 disease severity, 325 (5.74\%) received corticosteroids within the first 48 hours of admission. This patient population was observed to have 1.8 days longer length of hospital stay when compared to patients who received no corticosteroids during their hospitalization. No statistical significance was found in mortality.

Similarly, of the 1,873 patients that were considered severe to critical (ICU) COVID-19 disease severity, $338(18 \%)$ received corticosteroids within the first 48 hours of admission. This patient population had 1.9 days longer length of hospital stay and 1.4 times increase in mortality when compared to patients who did not receive corticosteroids during their hospitalization. No statistical significance was found in terms of time on a ventilator.

The differential effects in mild-moderate (non-ICU) versus severe-critical (ICU) patients is not surprising. In the most severely ill patients, the immune system shifts to a harmful overactive mode to fight the virus, triggering a cytokine storm, which causes organ injury. While reversing this hyper-inflammatory state is crucial to prevent lung damage, the timing is important, as the "early administration" based on hospital arrival may be different than the early administration based on the onset of severe symptoms. For example, patients with more than 8 days of symptoms will presumably be in the inflammatory phase of the disease and would benefit from anti-inflammatory therapies such as steroids.[30] However, when using high doses of steroids, it is necessary to perform an appropriate dose tapering. The patient's management should be based on a daily monitoring of blood pressure values, weight, serum sodium levels, and clinical symptoms that indicate adrenal impairment [36]. Another approach is the use of inhaled steroids rather than systemic 
administration. However, there is no evidence as to whether pre-morbid use or continued administration of inhaled corticosteroids is a factor for adverse or beneficial outcomes in acute respiratory infections due to coronavirus [37].

One recent meta-analysis concluded that the use of corticosteroids in critically ill COVID-19 patients did not improve or worsen mortality. Thus they recommended steroids for the patients with ARDS. [38] On the other hand, another meta-analysis by Yang et al [39] has found that corticosteroid treatment was associated with higher mortality, longer length of stay, a higher rate of infection, and hypokalemia, but not hyperglycemia or hypocalcemia [39]. This is consistent with our findings and supports our conclusion.

This led us to consider whether there was a correlation with the severity of the disease and steroid effects. With the fact that severe cases have a higher viral load but also a hyperactive innate immune system, the beneficial effect of steroids can be relevant for these cases, due to the reversal of the cytokine storm. On the other hand, suppression of the immune system in mild to moderate cases could be a harmful thereby reducing the ability to fight the virus.

Our findings show that "early" corticosteroid treatment in the non-ICU setting prolongs hospital length of stay but has no significant effect on mortality rate. The patients who had mild/moderate severity and received their initial dose of steroid within 48 hours of admission had a longer hospital stay without change in mortality. The severe/critical cases had increased risk of longer hospital stay and mortality with no change in ventilator time.

\section{STRENGTHS AND LIMITATIONS}

The main strength of our study is that the data involves 7,980 patients in 178 hospitals across the USA and the sample size for the corticosteroid group was 1,111. In order to assess the early administration of steroids, we have reviewed the patients given corticosteroids in the first 48 hours of hospital admission. However, admission time to the hospital may not reflect the de facto symptom onset. Also, we did not assess the data's physiological, laboratory, or viral parameters, which indicate the actual phase of the disease, i.e., early infection, pulmonary phase, or hyper-inflammation. Another limitation is that we did not compare type of the steroid, doses, duration, or side effects of corticosteroid use in the subgroups because of the lack of power.

\section{CONCLUSION}

To our knowledge, this study presents the largest number of COVID-19 positive patients in the USA on corticosteroid therapy. Despite the limitations, our study provides important data on corticosteroid therapy for COVID-19. Contrary to the beneficial effects claimed in some studies, we observed a worse outcome with corticosteroid therapy. The administration of systemic corticosteroids was associated with increases in disease severity, prolonged hospital stay, and mortality. Based on these results, we recommend cautious use of corticosteroids in COVID-19. Further research should be conducted to identify the factors precipitating the poor outcome associated with the use of corticosteroids in COVID-19.

\section{MATERIALS AND METHODS}

\subsection{Study design}

This is a retrospective observational cohort study involving 7980 patients in 178 hospitals of a nationwide health system across the US. This study was conducted in accordance with the Declaration of Helsinki and approved by the HCA Healthcare Institutional Review Board (IRB) Manager (Protocol no: 2020173).

\subsection{Data collection \& review}

All patients admitted to the hospitals between January 1, 2020 and May 8, 2020 and hospitalized for COVID-19 (ICD10 U07.1), confirmed by positive PCR test result from nasopharyngeal swab, were included in the study. Data was extracted from the enterprise electronic medical records (EMR) by a research analyst who prepared a de-identified data set. All study records were kept in a password protected study folder on a closed, enterprise-owned network. 


\subsection{Data Elements \& Outcomes}

Data elements included demographic information, comorbidities, medication, vitals, laboratory tests, treatments, and procedures, including invasive mechanical ventilation, conducted during hospitalization. The clinical outcomes were evaluated by disease severity (ICU level of care, mechanical ventilation and vasopressor support), time on ventilator, length of hospital stay, and mortality.

\subsubsection{Systemic Corticosteroid Use:}

The exposure to systemic corticosteroid was evaluated. Systemic corticosteroid use was defined as the use of any corticosteroid medication, including cortisone, hydrocortisone, prednisone, prednisolone, methylprednisolone, dexamethasone, and betamethasone during the hospital course. The route of administration was limited to either oral or intravenous. Topical and ophthalmic forms were excluded. The time of initiation of systemic corticosteroids was measured from hospital admission.

The institutional treatment protocol included the use of hydroxychloroquine + / - ribavirin, remdesivir, tocilizumab, and corticosteroids on case by case basis.

\subsection{Statistical Analysis}

All analysis in this study was completed using SAS (Version 9.4). P-values were assessed at the 95\% confidence level $(\alpha=0.05)$. Association between corticosteroid use and disease severity, mechanical ventilator time, length of hospital stay, and mortality was assessed using logistic regression models, controlling for age, sex, race, smoking status, comorbidities, and disease severity. Logistic regression models were also run to test for an association between disease severity and corticosteroids, controlling for age, sex, race, smoking status, and comorbidities.

Author contributions: Concept - B.Y., T.S.; Design - B.Y., T.S., E.T.; Supervision - T.S.; Resources - E.T., B.Y.; Materials - E.T.; Data Collection and/or Processing - B.Y., V.T.; Analysis and/or Interpretation - B.Y., N.Ş., V.T., T.S.; Literature Search - B.Y., N.Ş., T.S.; Writing - B.Y.; Critical Reviews - All authors.

Conflict of interest statement: The authors declared no conflict of interest.

Ethics committee approval: All experimental protocols were approved HCA Healthcare (Protocol number: 2020-173) on March 25, 2020.

\section{REFERENCES}

[1] Zhou P, Yang XL, Wang XG, Hu B, Zhang L, Zhang W, Shi, ZL. A pneumonia outbreak associated with a new coronavirus of probable bat origin. Nature. 2020; 579(7798): 270-273. [CrossRef]

[2] $\mathrm{Wu} \mathrm{JT}$, Leung K, Leung GM. Nowcasting and forecasting the potential domestic and international spread of the 2019nCoV outbreak originating in Wuhan, China: a modelling study. Lancet. 2020; 395(10225): 689-697. [CrossRef]

[3] Li Q, Guan X, Wu P, Wang X, Zhou L, Tong Y, Feng Z. Early transmission dynamics in Wuhan, China, of novel coronavirus-infected pneumonia. N Engl J Med. 2020; 382(13): 1199-1207. [CrossRef]

[4] CDC. United States COVID-19 Cases and Deaths by State. https://covid.cdc.gov/covid-datatracker/\#cases_casesper100klast7days, (accessed on 4 May 2021).

[5] Dolhnikoff M, Duarte-Neto AN, de Almeida Monteiro RA, da Silva LFF, de Oliveira EP, Saldiva PHN, Negri EM. Pathological evidence of pulmonary thrombotic phenomena in severe COVID-19. J Thromb Haemost. 2020; 18(6): 1517-1519. [CrossRef]

[6] Carsana L, Sonzogni A, Nasr A, Rossi RS, Pellegrinelli A, Zerbi P, Nebuloni M. Pulmonary post-mortem findings in a series of COVID-19 cases from northern Italy: a two-centre descriptive study. Lancet Infect Dis. 2020; 20(10): 11351140. [CrossRef]

[7] Banwait RSS, Joshua K, Fishman TJ, Uma GI. Convalescent plasma in COVID-19. HCA Healthcare Journal of Medicine. 2020; 1(3):139-146. [CrossRef]

[8] Jean SS, Lee PI, Hsueh P R. Treatment options for COVID-19: The reality and challenges. J Microbiol Immunol Infect. 2020; 53(3): 436-443. [CrossRef]

[9] Kalil AC. Treating COVID-19-off-label drug use, compassionate use, and randomized clinical trials during pandemics. Jama. 2020; 323(19): 1897-1898. [CrossRef] 
[10] Mehta N, Mazer-Amirshahi M, Alkindi N, Pourmand A. Pharmacotherapy in COVID-19; a narrative review for emergency providers. Am J Emerg Med. 2020; 38(7): 1488-1493. [CrossRef]

[11] Veronese N, Demurtas J, Yang L, Tonelli R, Barbagallo M, Lopalco P, Smith L. Use of corticosteroids in coronavirus disease 2019 pneumonia: a systematic review of the literature. Front Med (Lausanne). 2020; 7: 170. [CrossRef]

[12] Siordia JA Jr, Bernaba M, Yoshino K, Ulhaque A, Kumar S, Bernaba M, Bergin E. Systematic and statistical review of coronavirus disease 19 treatment trials. SN Compr Clin Med. 2020; 2: 1120-11311. [CrossRef]

[13] Huang C, Wang Y, Li X, Ren L, Zhao J, Hu Y, Cao B. Clinical features of patients infected with 2019 novel coronavirus in Wuhan, China. Lancet. 2020; 395(10223): 497-506. [CrossRef]

[14] Kolilekas L, Loverdos K, Giannakaki S, Vlassi L, Levounets A, Zervas E, Gaga M. Can steroids reverse the severe COVID-19 induced "cytokine storm"? J Med Virol. 2020; 92(11): 2866-2869. [CrossRef]

[15] Sibila O, Agustí C, Torres A. Corticosteroids in severe pneumonia. Eur Respir J. 2008; 32(2): 259-264. [CrossRef]

[16] Stern A, Skalsky K, Avni T, Carrara E, Leibovici L, Paul M. Corticosteroids for pneumonia. Cochrane Database Syst Rev. 2017; 12(12): CD007720. [CrossRef]

[17] Yang JW, Yang L, Luo RG, Xu JF. Corticosteroid administration for viral pneumonia: COVID-19 and beyond. Clin Microbiol Infect. 2020; 26(9): 1171-1177. [CrossRef]

[18] Lansbury L, Rodrigo C, Leonardi-Bee J, Nguyen-Van-Tam J, Lim WS. Corticosteroids as adjunctive therapy in the treatment of influenza. Cochrane Database Syst Rev. 2019; 2(2): CD010406 [CrossRef]

[19] Nasim S, Kumar S, Azim D, Ashraf Z, Azeem Q. Corticosteroid use for 2019-nCoV infection: A double-edged sword. Infect Control Hosp Epidemiol. 2020; 41(10): 1244-1245. [CrossRef]

[20] Tang C, Wang Y, Lv H, Guan Z, Gu J. Caution against corticosteroid-based COVID-19 treatment. Lancet. 2020; 395(10239): 1759-1760. [CrossRef]

[21] WHO. Clinical management of COVID-19. https://www.who.int/publications-detail/clinical-management-ofsevere-acute-respiratory-infection-when-novel-coronavirus-(ncov)-infection-is-suspected, (accessed on 6 July 2020).

[22] Berton AM, Prencipe N, Giordano R, Ghigo E, Grottoli S. Systemic steroids in patients with COVID-19: pros and contras, an endocrinological point of view. J Endocrinol Invest. 2021; 44(4): 873-875. [CrossRef]

[23] Chen RC, Tang XP, Tan SY, Liang BL, Wan ZY, Fang JQ, Zhong N. Treatment of severe acute respiratory syndrome with glucosteroids: the Guangzhou experience. Chest. 2006; 129(6): 1441-1452. [CrossRef]

[24] Wang y, Jiang W, He Q, Wang C, Liu B, Zhou P, Dong N, Tong Q. Early, low-dose and short-term application of corticosteroid treatment in patients with severe COVID-19 pneumonia: single-center experience from Wuhan, China. medRxiv 2020.03.06.20032342: [CrossRef]

[25] Zha L, Li S, Pan L, Tefsen B, Li Y, French N, Villanueva EV. Corticosteroid treatment of patients with coronavirus disease 2019 (COVID-19). Med J Aust. 2020; 212(9): 416-420. [CrossRef]

[26] Fang X, Mei Q, Yang T, Li L, Wang Y, Tong F, Pan A. Low-dose corticosteroid therapy does not delay viral clearance in patients with COVID-19. J Infect. 2020; 81(1): 147-178. [CrossRef]

[27] Ling Y, Xu SB, Lin YX, Tian D, Zhu ZQ, Dai FH, Lu HZ. Persistence and clearance of viral RNA in 2019 novel coronavirus disease rehabilitation patients. Chin Med J (Engl). 2020; 133(9): 1039-1043. [CrossRef]

[28] $\mathrm{Wu}, \mathrm{C}$, Chen X, Cai Y, Xia J, Zhou X, Xu S, Song Y. Risk factors associated with acute respiratory distress syndrome and death in patients with coronavirus disease 2019 pneumonia in Wuhan, China. JAMA Intern Med. 2020; 180(7): 934-943. [CrossRef]

[29] Liu K, Fang YY, Deng Y, Liu W, Wang MF, Ma JP, Liu HG. Clinical characteristics of novel coronavirus cases in tertiary hospitals in Hubei Province. Chin Med J (Engl). 2020; 133(9): 1025-1031. [CrossRef]

[30] Cruz AF, Ruiz-Antorán B, Múñez Rubio E, López AS, Callejas Díaz A, Avendaño-Solá C, Martínez AR. The right time for steroids in COVID-19. Clin Infect Dis. 2020; ciaa865. [CrossRef]

[31] Horby P, Lim WS, Emberson JR, Mafham M, Bell JL, Linsell L, Landray MJ. Dexamethasone in hospitalized patients with Covid-19 - preliminary report. N Engl J Med. 2020; 384(8): 693-704. [CrossRef]

[32] Selvaraj V, Dapaah-Afriyie K, Finn A, Flanigan TP. Short-term dexamethasone in Sars-CoV-2 patients. R I Med J. 2020; 103(6): 39-43

[33] Fadel R, Morrison, AR, Vahia A, Smith ZR, Chaudhry Z, Bhargava P, Ramesh MS. Early short-course corticosteroids in hospitalized patients with COVID-19. Clin Infect Dis. 2020; 71(16): 2114-2120. [CrossRef] 
[34] National Health Commission \& National Administration of Traditional Chinese Medicine. Diagnosis and treatment protocol for novel coronavirus pneumonia (Trial version 7). Chin Med J (Engl). 2020; 133(9): 1087-1095. [CrossRef]

[35] Fernández-Cruz A, Ruiz-Antorán B, Muñoz-Gómez A, Sancho-López A, Mills-Sánchez P, Centeno-Soto G A, Avendaño-Solá C. A retrospective controlled cohort study of the impact of glucocorticoid treatment in SARS-CoV-2 infection mortality. Antimicrob Agents Chemother. 2020; 64(9): e01168-20. [CrossRef]

[36] Scaroni C, Armigliato M, Cannavò S. COVID-19 outbreak and steroids administration: are patients treated for SarsCov-2 at risk of adrenal insufficiency? J Endocrinol Invest. 2020; 43(7): 1035-1036. [CrossRef]

[37] Halpin DMG, Singh D, Hadfield RM. Inhaled corticosteroids and COVID-19: a systematic review and clinical perspective. Eur Respir J. 2020; 55: 2001009 [CrossRef]

[38] Gangopadhyay KK, Mukherjee JJ, Sinha B, Ghosa S. The role of corticosteroids in the management of critically ill patients with coronavirus disease 2019 (COVID-19): A meta-analysis. medRxiv 2020.04.17.20069773. [CrossRef]

[39] Yang Z, Liu J, Zhou Y, Zhao X, Zhao Q, Liu J. The effect of corticosteroid treatment on patients with coronavirus infection: a systematic review and meta-analysis. J Infect. 2020; 81(1): e13-e20. [CrossRef]

This is an open access article which is publicly available on our journal's website under Institutional Repository at http://dspace.marmara.edu.tr. 